INTERNATIONAL JOURNAL OF SYSTEMATIC BACTERIOLOGY

Vol. 20, No. 4 October 1970

Copyright 1970, Iowa State University Press

\title{
IMPORTANCE OF THE BIOCHEMICA L COMPOSITION OF THE CELL WALL AS A TAXONOMIC CHARACTERISTIC
}

\author{
A. R. Prévot ${ }^{1}$ \\ Institute Pasteur, Paris
}

For a long time I have been convinced of the taxonomic value of the morphology and the biochemical composition of bacteria cell walls, and I expressed the basis of this conviction in 1961 in the chapter "Cellwalls" in my treatise on systematic bacteriology (Prévot 1961).

I. Wall morphology has always been used, even before recognition of the cytochemical and cytophysiological individuality of cell walls. It gave rise to natural groups such as Micrococcales, Bacteriales, Spirillales Spirochetales, etc. Electron microscopy later confirmed and defined more clearly the characteristics demonstrated by light microscopy and introduced new characters such as the morphology and arrangement of the macromolecules of the various cell wall layers.

II. It is especially in its biochemical character (which comprise the crystalline systems of each of the constituents) that it provides taxonomy with specific, generic, or family characteristics. In the course of extensive studies, I have given numerous examples of this specificity without being able to exhaust this vast subject. For example, in E. coli the arrangement of hydrocarbon chains of the wall lipids (which are different from the lipids of other species) perpendicular to the cellular surface, provides a precise taxonomic characteristic. In the same species, the specificity of the wall polyosides and the presence of colitose, different from the polyosides of Salmonella (tyvelose, abequose, and paratose) provides a second series of characters.

The role of polyosides in $O$ antigens is widely used for the classification of Salmonella.

The proteins bound to the polyosides and to the lipids also provide important specific and generic characteristics especially in the Gramnegative families.

Since the discovery of diaminopimelic acid all authors recognize that the isomeric structure is specific: LL., DD., meso-, etc., each characterizing a species or group of species.

Muramic acid is associated with the glucides in many different ways according to species. The problem of the differentiation of the species bifidum from the genus Lactobacillus has been resolved by studies of its cell wall comparison with that of the lactobacilli. The biochemical characteristics of the two groups are clearly different and justify the systematic position of the species bifidum in the genus Bifidobacterium Orla-Jensen, very close to the genus Actinobacterium Hass, and very far from Lactobacillus. The mucopeptide, because of the diversity of its constituents, is a characteristic of high specificity. The teichoic acids

Dr. Prevot was unfortunately unable to attend the meeting, but submitted this short statement of his views for publication with the other papers to the symposium. 
are even more varied; the group with ribitol-phosphate is contrasted with the group with glycerol-phosphate, and the variety of the amino acid chains which are bound to them adds to that diversity.

Thus I concluded in 196.1 "the taxonomic potential which the cell walls of bacteria can offer is very great; specificity of the physical structure, specificity of the chemical structure, specificity of the antigenic structure, . . . From now on there will be more and more utilization of the se characteristics for the differentiation of bacterial species."

Recent personal research

Since 1950 I have had a strong interest in the group of anaerobic corynebacteria and the infections which they cause. I have shown:

1. Their affinity for the reticuloendothelial system.

2. The experimental disease, which is an acute histioreticulosis (granuloma) with large multinucleate plasma cells of hyperenergetic character (many giant cells), similar to the naturally occurring disease.

3. The recitulo-stimulatory substance is independent of the reproduction of the bacteria which synthesize it since it is present in the microbial cells which have been killed by heat or formalin.

4. The reticulo-stimulin is a characteristic of the group because it is synthesized by all of the pathogenic species of anaerobic corynebacteria. Now with my collaborators Tam-Nguyen-Dang and Thouvenot, I can locate the site of synthesis of this stimulatory substance in the cell wall (Prévot et al. 1968).

The property of synthesizing the reticulo-stimulin is common to all of the anaerobic species of the genus. Therefore, there will be reason to clearly separate the two groups. It would be advantageous to move the anaerobic group closer to the genus Propionibacterium because several species of that genus synthesize small quantities of a substance similar to the reticulo-stimulin.

We still do not know what group of compounds the reticulo-stimulin is associated with, but we know that it is an extremely labile complex because, so far, all attempts to isolate and fractionate it have failed. But these failures do not prevent us from attributing a taxonomic value to it now, to be added to all the other cell wall properties cited which are useful to taxonomists.

\section{REFERENCES}

Prévot, A.R. 1961. Traite de Systematique bacterienne. Vol. I, pages 120-137. Dunod - Paris. , Tam-Nguyen-Dang et Thouvenot. 1968. C.R. Ac. Sc. 267:1061. 